Delineation of post-phloem assimilate transport pathway into developing caryopsis of Brachypodium distachyon

Charles Ugochukwu Solomon ${ }^{1,2}$

Sinead Drea ${ }^{1}$

${ }^{1}$ Department of Genetics and Genome Biology, University of Leicester, University Road, Leicester LE1 7RH, UK

${ }^{2}$ Abia State University, Uturu, PMB 2000 Uturu, Nigeria

Email: cus2@le.ac.uk; sd201@le.ac.uk

Phone: +447835298029

Date of submission:

Number of tables: 0

Number of figures: 4

Word count: 4668 


\section{Delineation of post-phloem assimilate transport pathway into developing caryopsis of Brachypodium distachyon}

\section{Highlights}

- Based on existing work, we propose Caryopsis Endosperm Assimilate Acquisition Route (CEAAR) models, that describes the exact path of assimilate import into caryopsis endosperms.

- The structure of the post-phloem transfer cells of Brachypodium distachyon mirrors temperate and tropical cereals.

\section{Abstract}

Assimilates stored in mature cereal grains are mobilized from source tissues and transported towards developing grains through the vascular bundle. Due to the lack of direct vascular connection between maternal grain vascular bundle and filial tissues, post-phloem transportation of assimilates into grain endosperm relies on transfer cells that lie between the grain vascular bundle and the endosperm. Here, we propose Caryopsis Endosperm Assimilate Acquisition transfer cells of Brachypodium and those of crop species such as rice, wheat, and barley relevant to post-phloem assimilate transport.

Key words; Assimilate, Brachypodium, Cereals, Endosperm, Transfer cells, Transport

\section{Abbreviations}

bd : basal direct

IPC: Inner Pericarp Cells 
vc: ventral circuituous

vd: ventral direct

\section{Introduction}

Cereals are major source of food and feed for humans and their livestock. The value of cereals lies in the dry storage capacity of their endosperm. An endosperm is a sink tissue, therefore assimilates stored in the endosperm originate from source tissues in other parts of the plant. During grain filling, assimilates are translocated from source tissues towards the endosperm through the vascular bundle. Because of the absence of vascular continuity between maternal source tissues and filial sink tissues, assimilates are unloaded from the phloem and traverse post-phloem transfer cells on their journey to the endosperm. Thus, the post-phloem transport pathway serves as a bridge connecting maternal supply to filial sink of cereal caryopsis. Based on studies of assimilate movement into developing filial tissues of cereals like rice, maize, sorghum, barley and wheat, three models for post-phloem transport pathway into caryopses endosperms can be deduced. These models, which we collectively termed Caryopsis Endosperm Assimilate Acquisition Route (CEAAR) models are; basal direct (bd), ventral circuitous (vc), ventral direct (vd) and (Fig. 1). Barley and wheat represent the first model; vd-CEAAR. In these species, assimilates are also delivered by a ventrally located grain vascular tissue that run the length of the grain. On exit from the phloem, assimilates symplastically cross chalazal cells, nucellar projection cell sand accumulate temporally in an apoplastic space called the endosperm cavity. Specialized endosperm transfer cells (also called modified aleurone cells) handles the importation of assimilates from the endosperm cavity into the endosperm (Fig. 1a) (Cochrane, 1985;Cochrane and Duffus, 1980; Donovan et al., 1983; Frazier and Appalanaidu, 1965; H. L.Wang, C. E. Offler, et al., 1995; H. L. Wang, J. W. Patrick, et al., 1995; Zheng and Wang, 2011).

An example of vc-CEAAR is found in rice, where assimilates are delivered by the ovular vascular tissue that runs the entire length of the ventral surface of developing rice grains.

Assimilates symplastically traverse the chalazal zone, a remnant of nucellar and move into nucellar epidermis cells. Within the nucellar epidermis, they move circumferentially around the developing endosperm and eventually cross the plasma membrane of the nucellar epidermis cell into an apoplastic space adjoining the aleurone cells. From this space they are imported into aleurone cells and further into starchy endosperm cells (Fig. 1b) (Ellis and Chaffey, 1987; Krishnan and Dayanandan, 2003; Oparka and Gates, 1981, 1982; Wu et al., 2016). The third model, bd-CEAAR, is seen in maize and sorghum. Here the vascular trace ends at the base of the grain. Assimilates 
74 headed for storage in the endosperm are released from the phloem sieve tubes, from there they cross

75 the chalazal strip and remnant nucellar cells. In sorghum and some varieties of maize, assimilates

76 accumulate in the placental sac which serves as a transient sink. Basal Endosperm transfer layer

77 (BETL) cells are responsible for transport of assimilates from the placental sac into the developing endosperm (Fig. 1c) (Felker and Shannon, 1980; Maness and McBee, 1986; Thorne, 1985; Zheng et al., 2015).

The importance of post-phloem assimilate transfer cells for proper caryopses development is easily manifest when there is perturbation of normal gene regulation and expression in the transfer cells. For example, maize MINIATURE1 (MN1) and rice GRAIN INCOMPLETE FILLING (GIF1) loci encodes cell wall invertases that are expressed in the transfer cells of maize and rice grains respectively. Null mutation of MN1 or mis-regulation of GIF1 results in smaller grains compared to wild type (Cheng et al., 1996; Miller and Chourey, 1992; Wang et al., 2008). Similarly in barley, mature grains of shrunken endosperm genetic (seg); seg1, seg3, seg6 and seg7 mutants are shrunken because post-phloem transfer cells collapse early compared to wild type, leading to premature cessation of grain filling (Bosnes et al., 1992; Felker et al., 1985, 1984, 1983). Furthermore, maize $Z m S W E E T 4 c$ and its rice ortholog OsSWEET4 are hexose transporters expressed in post-phloem transfer cells. Their loss of function mutation results in incomplete grain filling (Sosso et al., 2015). In view of the importance of the expression of GIF1, OsSWEET4 and ZmSWEET4c in the postphloem transfer cells of rice and maize respectively, for proper grain filling, they no doubt contribute to large grain trait of these cereals and are therefore postulated to have been recruited during the domestication of these cereals (Doebley et al., 2006; Sosso et al., 2015; Wang et al.,

Brachypodium distachyon (subsequently, Brachypodium) on the other hand is a wild grass that recently became a model system for temperate cereals. Brachypodium grains are comparable to barley and wheat in length, but are narrower in width and shallower in depth (Hands and Drea, 2012). Although, median transverse section profiles of Brachypodium grains are generally identical

102 to barley, wheat and oat sections, Brachypodium grains have reduced nucellar projection and 103 persistent nucellar epidermis (Kosina and Tomaszewska, 2016; Opanowicz et al., 2011). Notably, modified aleurone, critical for assimilate import into the endosperm of barley and wheat is absent in

105 Brachypodium grains. This attribute suggests that the final step of assimilate import into

106 Brachypodium endosperm employs a different route compared to wheat and barley. Hence, we 107 speculated that assimilate movement into Brachypodium endosperm follows the vc-CEAAR model 
108

109

110

111

112

113

114

115

116

as found in rice (Hands et al., 2012). In this study, we used fluorescent dyes; 5-(6)-6 carboxyfluorescein diacetate (CFDA) and Lucifer Yellow (LW) to trace the path of assimilate movement into Brachypodium endosperm.

We confirm that the route of assimilate import into Brachypodium endosperm is similar to rice and can be classified as vc-CEAAR. In addition, we report detailed ultrastructural study of caryopsis post-phloem transfer cells of Brachypodium. Our results highlight the anatomical basis for the route of assimilate transport into Brachypodium endosperm. Structural similarities and differences between the caryopses post-phloem transfer cells of Brachypodium and major cereals relevant to assimilate import into the endosperm are discussed.

\section{Materials and Methods}

\section{Growth of Brachypodium plants}

Brachypodium (Bd 21) Grains, were imbibed on moist filter paper in a Petri dish and left at $5^{\circ} \mathrm{C}$ for two days to vernalize. They were transferred to room temperature (about $25-27^{\circ} \mathrm{C}$ ) and left to germinate. After 7 days, the most virile seedlings were transferred to 9:1 Levington M2 Pot and Bedding Compost: Levington Fine Vermiculite mix (dejex.co.uk), in Vacapot ${ }^{\mathrm{TM}} 15$ on plastic seed trays (www.plantcell.co.uk). They were grown in the greenhouse at $16 \mathrm{hr}$ daylight and $25^{\circ} \mathrm{C}$ temperature. The plants were regularly watered manually. Flowering spikes were tagged at anthesis and sampled at 5 days interval after anthesis until 30 days post anthesis (DPA).

\section{Fluorescence tracer experiments}

Fluorescence dyes used are symplastic tracer; 0.01\% 5-(6)-6-carboxyfluorescein diacetate (CFDA; Sigma) and apoplastic tracer; 1\% Lucifer Yellow (LY; Sigma). Sterile distilled water served as control. Brachypodium grains were carefully detached from their rachis at 20 DPA and their lemma removed under a dissecting microscope. About 20 grains were incubated in $1 \mathrm{ml}$ solution of either fluorescent dyes or water in $1.5 \mathrm{ml}$ Eppendorf tubes at room temperature.

Five grains were sampled from each treatment at 15,30, 45 and 60min. This was followed by a vigorous rinse in $1 \mathrm{ml}$ distilled water three times before the grains were transferred to $0.5 \mathrm{ml} 50 \%$ glycerol. Free hand $80-150 \mu \mathrm{m}$ transverse sections spanning the length of the grains were made with clean razor blades. The sections were mounted on $50 \%$ glycerol covered with cover slips and the edges sealed with nail varnish. Imaging was done with Nikon ECLIPSE 80i fluorescence microscope (Nikon, Japan), having an LED-based excitation source (CoolLED, presicExcite), using 
142 Nikon Plan Fluor 10x /0.30 DIC L/N1 objective lens. Fluorescence images were captured with a

143 DS-QiMc cooled CCD camera (Nikon, Japan). Images were previewed, captured and saved using

144 NIS-Elements Basic Research v3.0 software (Nikon, Japan) in JPEG2000 format.

145

146 Brachypodium grain processing for light and transmission electron microscopy

147 Individual Brachypodium florets were tagged at anthesis and developing grains were sampled at

148 five days interval until 30 days after anthesis (DPA), six developmental stages in total. At each

149 interval, five grains were collected from different florets. $1 \mathrm{~mm}$ section was cut from the mid grain

150 region of each grain, using a dissecting microscope. Sections were fixed in $2.5 \%$ glutaraldehyde in

$1510.1 \mathrm{M}$ sodium Cacodylate buffer $\mathrm{pH} 7.4$, for 3 days at $4^{\circ} \mathrm{C}$ with constant gentle agitation and then

152 washed in $0.1 \mathrm{M}$ Sodium Cacodylate buffer. After further fixation in $1 \%$ aqueous osmium tetroxide

153 and dehydration in series of increasing ethanol concentrations followed by propylene oxide, the

154 seed sections were embedded in Spurr's hard resin and polymerised for 16 hours at $60^{\circ} \mathrm{C}$.

155

156 Light microscopy

157 Grain sections for light microscopy were cut 400nm thick, stained with $0.01 \%$ toluidine blue,

158 mounted in resin, then viewed and photographed with GX L3200B compound microscope

159 (gtvision.co.uk) equipped with a CMEX-5000 USB2 Microscope camera and ImageFocus 4

160 software (euromex.com). Images were stored as TIFF files and annotated with Adobe

161 Illustrator.

162

163 Electron microscopy

$16470 \mathrm{~nm}$ thick sections for transmission electron microscopy were cut using a Reichert Ultracut

165 E ultra microtome. The sections were collected onto copper mesh grids, and stained with

$1662 \%$ aqueous uranyl acetate for 30 minutes followed by 5 minutes in lead citrate. Sections were

167 viewed on a JEOL JEM-1400 TEM (www.jeolusa.com) with an accelerating voltage of

$168100 \mathrm{kV}$. Digital images were collected with a Megaview III digital camera with iTEM software

169 (emsis.eu) as TIFF files.

170

\section{Results}

172 Cellular structure of assimilate transfer route in Brachypodium grains

173 Vascular bundle

174 Groups of sieve element - companion cells (se - cc) complex was observed on the ventral 
175 (adaxial) vascular bundle on all the grains sampled at all stages. The number of se - cc complex

176 varied between grains at the same developmental stage but generally increased as the grain

177 develops. Characteristic of monocots, the se - cc complexes were irregularly scattered between

178 vascular parenchyma cells (Fig. 2b, d-g), except at 10 DPA when they seemingly formed a semi-

179 circle facing towards the pigment strand (Fig. 2a, c). Mixtures of mature (empty lumen) and

180 immature (lumen with remnants of cytoplasm) sieve elements cells were observed in all sample

181 stages (Fig. 3a). The accompanying companion cells were not always easily identified. They were

182 smaller and usually had denser cytoplasm compared to vascular parenchyma cells (Fig. 3a).

183 Plasmodesmata connections were observed between sieve elements and their companion cells, as

184 well as between sieve elements and vascular parenchyma cells. Similarly, there were

185 plasmodesmata connections between companion cells and vascular parenchyma cells. Remarkably,

186 we could not identify any xylem elements in sections from all the stages.

187

188

Pigment strand

189 The pigment strand is located inwards of the vascular bundle toward the endosperm. The pigment

190 strand is remarkable for cells that accumulate dark deposits as the grain develops. At

1915 DPA, the cells of the pigment strand can be distinguished from those of vascular parenchyma

192 bundles by their elongate shape and generally denser cytoplasm. Dark deposits were detected on a

193 few of the cells in the pigment strand at 5DPA. They appeared to first accumulate in small amount,

194 in a subcellular organelle, possibly the vacuole. The organelle then enlarges, with the already

195 accumulated deposit forming a continuous ring bordering the membrane of the organelle. The rest

196 of the cytoplasm is pushed against the cell wall as the organelle expands. The initial clear space

197 created within the organelle by its enlargement is eventually filled with the dark deposit as the grain

198 matures (Fig. 2a-g; Fig. 3b-d). The number of pigment strand cells filled with dark deposit

199 increased at subsequent sampling stages. Note that even at 30 DPA, there were still pigment strand

200 cells that had not accumulated dark deposits. Abundant plasmodesmata connections were observed

201 between adjacent pigment strand cells (whether filled with dark deposit or not), between pigment

202 strand cells and vascular parenchyma cells, and, between pigment strand cells and nucellar

203 projection cells (Fig. 3).

204

205 Four layers of different cell types flank the pigment strand on both sides and are continuous round

206 the developing endosperm (Fig. 2a-b). They are tube cells (CC), outer integument

207 (OI), inner integument (II) and nucellar epidermis (NE), in that order from the outer surface.

208 For brevity we will refer to them as inner pericarp cells (IPC). 
210 Tube cells are bordered on the outside by mesocarp cells and on the inside by the outer integument.

211 They are easily distinguished from the mesocarp cells by their lack of chloroplasts, circular shape

212 and sparse cytoplasm. Tube cells had thin cell walls in all the samples examined and enlarge as the

213 grain develops till around 20 DPA. They subsequently appeared shrunk in size and separate from

214 one another by 30 DPA.

216 The outer integument cells have sparse cytoplasm and enlarge as the grain develops till about

21720 DPA. The cell walls of outer integument cells adjacent to tube cells are already cutinized at 5

218 DPA and progressively become heavily cutinized as the grain matures (Fig. 2b-g). The inner cell

219 walls abutting the inner integument also become cutinized to a lesser degree as the grain develops.

220 From 25 DPA, outer integument cells collapse and appear as one layer of cutin. The collapse of the outer integument cells starts from the dorsal grain surface and proceeds to the ventral surface.

Inner integument cells lie between the outer integument and nucellar epidermis. Inner integument cells are filled with dark deposits in the manner already described for pigment strand cells. The deposits have been identified in barley as tannins (Briggs, 1974; Felker et al., 1984).

Nucellar epidermis cells are the largest of the cell types in a developing Brachypodium grain at 5 DPA (Fig. 2a). The lateral nucellar epidermis cells are usually the largest (Opanowicz et al., 2011). Nucellar epidermis cells reach peak size at about 15 DPA. Subsequently, they gradually become smaller, possibly as a result of pressure from the expanding endosperm. Adjacent nucellar epidermis cells are separated by thin cell walls with prominent plasmodesmata.

232 However, nucellar epidermis cell walls in contact with endosperm cells and inner integument cells 233 are greatly thickened (Fig. 3e). Gullion et al, (2012), detected (1-3) (1-4)- $\beta$-D glucan in the inner 234 and outer cell walls of nucellar epidermis cells in 7 DPA developing Brachypodium grains. The 235 cytoplasm of nucellar epidermis cells appeared vacuolated at early stages of development. At later 236 stages of development the cells were found filled with electron lucent cellulosic material, previously 237 identified as (1-3) (1-4)-b-D glucan (Guillon et al., 2012). A prominent middle lamella was 238 observed between nucellar epidermis cells and inner integument cells (Fig. 3e).

240 There are plasmodesmata connections between adjacent pigment strand cells and cells of these four 241 cell types on both flanks. Plasmodesmata connections were not observed between the different 242 types of cells that make up the IPC. 
245 Nucellar projection cells adjoins the pigment strand inwards towards the endosperm. Brachypodium 246 nucellar projection cells can be distinguished into two types; (a) smaller and circular type close to the pigment strand that have dense cytoplasm, (b) larger and elongate type close to the endosperm that have sparse cytoplasm (Fig. 2). The cell walls of nucellar projection cells greatly thicken as the grain matures, especially the elongate nucellar cells close to the endosperm (Fig. 3f). A progressive increase in the cell wall thickening of nucellar projection cells from the pigment strand to the endosperm was observed. Signs of lysing of nucellar projection cells close to the endosperm were observed on grain sections from 10 - 30 DPA.

253 Numerous plasmodesmata connections were observed between adjacent nucellar projection cells.

\section{Endosperm cavity}

256 Endosperm cavity was not observed on Brachypodium grains sampled at 5 and 10 DPA. At

25715 DPA (Fig. 2d), endosperm cavity was observed between the endosperms and nucellar projection.

258 The cavity was still present at 20 DPA (Fig. 2e), though occupying a lesser area compared to 15

259 DPA. By 25 DPA, the cavity has been completely occluded by the expanding endosperm (Fig. 2f).

\section{Assimilate transfer pathway into developing Brachypodium grains}

262 Delineation of assimilate transport pathway into developing Brachypodium grains was investigated 263 using fluorescent dyes; symplastic tracer; 5-(6)-6-carboxyfluorescein diacetate (CFDA; Sigma) and 264 apoplastic tracer; 1\% Lucifer Yellow (LY; Sigma). The grains were incubated in the dye solutions 265 for different lengths of time and the localization of the dyes were confirmed using fluorescence 266 microscopy.

CFDA was readily observed on transverse free hand sections of the Brachypodium grains that had been incubated in the dye for $15 \mathrm{~min}$. CFDA fluorescence was distinctly observed on the vascular

270 bundle, pigment strand cells, nucellar projection cell and round the grain in nucellar epidermis cells 271 (Fig. 4). Similar, results were obtained on grains incubated in the dye for 30, 45 and 60min. As the 272 period of incubation increased, dye fluorescence increased centripetally in the endosperm. This 273 suggests that materials travel circumferentially around the grain and at some point cross into 274 endosperm cells. So the longer the grains were incubated, the more CFDA is centripetally 275 accumulated, evidenced by intense fluorescence in the endosperm of grains sectioned after 60min 276 incubation in CFDA (data not shown). 
278 Fluorescent signals were not detected in sections of Brachypodium grains incubated in Lucifer

279 Yellow for any of the period of time used in this experiment (data not shown). Since Lucifer yellow

280 is an apoplastic dye, this suggests that assimilate movement into Brachypodium endosperm may be 281 largely symplastic.

282

\section{Discussion}

284 The succession of cell types in the post-phloem assimilate delivery pathway of Brachypodium 285 represent a combination of features of such pathways reported in wheat, barley and rice. A ventral 286 vascular bundle that spans the length of the caryopsis is a common feature in these three species 287 (Thorne, 1985). The grain vascular bundle is connected to the rachilla and serves as route of water 288 and assimilate transport from the rest of the plant into developing caryopsis (Frazier and Appalanaidu, 1965; Lingle and Chevalier, 1985). Our observation of the formation of semi-circle by the phloem of the vascular bundle of Brachypodium grains at 10 DPA (Fig. 2a, c) corresponds to observation of a phloem arc in rice caryopsis at 12 DPA (Oparka and Gates, 1981). The occurrence of immature sieve elements containing little cytoplasm alongside mature sieve elements with empty

293 lumen has also been reported in rice (Oparka and Gates, 1981). Since the vascular bundle continue

294 to differentiate as the grain develops, the immature sieve elements observed may be newly

295 differentiated ones. Plasmodesmata connection among and between cells of the vascular bundle of

296 Brachypodium grains suggest symplastic exchange of water and assimilates between these cells.

297 This is similar to observations in rice and wheat (Oparka and Gates, 1981; H. L. Wang, C. E. Offler, et al., 1995). Also, Plasmodesmata connection between cells of the vascular bundle and surrounding parenchyma cells is consistent with observations in wheat (H. L. Wang, C. E. Offler, et al., 1995).

300 This arrangement of cells suggest that assimilates move vertically up from the base of the grain

301 through the vascular bundle and are discharged horizontally into the parenchyma cells along the 302 way.

304 Sucrose is the main sugar transported in grasses (Thorne, 1985; van Bel and Hess, 2008).

305 Sucrose is cleaved to hexoses on exit from the vascular bundle in maize and sorghum by vacuolar 306 and cell wall invertases (Bihmidine et al., 2013; Felker and Shannon, 1980; Maness and McBee, 307 1986; Porter et al., 1985). In wheat and barley, whether or not sucrose is cleaved after it is unloaded 308 from the vascular bundle remains a debate (Thorne, 1985). In any case, accumulation of glucose in 309 wheat endosperm cavity sap coupled with $80 \%$ reduction of sucrose concentration compared to 310 sieve tube sap strongly suggests that sucrose is cleaved in the post-phloem transfer cells of wheat 
311 (Fisher and Gifford, 1986). Whether or not sucrose is transformed in the post-phloem pathway of

312 Brachypodium is an interesting research question. However, the dense cytoplasm of the vascular

313 bundle and parenchyma cells suggest they are not just passive channels of for assimilate movement.

314 The abundance of mitochondria in these cells suggest the occurrence of energy demanding

315 processes. This sharply contrasts with surrounding mesocarp cells which gradually lose their

316 cytoplasm as the grain develops, and but for chloroplasts, appear empty at 30 DPA.

318 The presence of pigment strand have been reported in barley rice and wheat (Felker et al., 1984;

319 Oparka and Gates, 1982; H. L. Wang, C. E. Offler, et al., 1995). While the pigment strand cells of 320 rice grain accumulate lipid deposits, those of wheat and barley accumulate phenolic deposits (Felker et al., 1984; Oparka and Gates, 1982). The pigment strand in Brachypodium is strikingly similar to

322 barley in the extent it gets filled with dark deposits (Lingle and Chevalier, 1985). Dark deposits in Brachypodium pigment strand cells were visible at 5 DPA whereas they appears at about 12 DPA in barley (Felker et al., 1984; Lingle and Chevalier, 1985), suggesting early accumulation of dark deposits in Brachypodium. The accumulation of deposits in pigment strand cells was initially thought to limit assimilate transport towards the endosperm during wheat grain development (Zee and O'brien, 1970). Subsequent reports failed to confirm this view, but rather suggested that assimilate transport is restricted to the symplast at the pigment strand (Lingle and Chevalier, 1985; Oparka and Gates, 1982). On the basis of comparative anatomy, we speculate that assimilate 330 movement into developing Brachypodium grains may not be limited by the accumulation of dark deposits in its pigment strand cells. Whether assimilate transport is restricted to the symplast at the pigment strand of Brachypodium cannot be firmly confirmed from our results. However, the high

333 frequency of plasmodesmata connection between pigment strand cells and vascular parenchyma

334 cells suggest an increased transportation capacity that may compensate for loss of apoplastic transport between the vascular parenchyma cells and the pigment strand cells.

Plasmodesmata connection between pigment strand cells and IPC, namely; tube cells, outer integument, inner integument and nucellar epidermis, suggest that assimilate supply to these cells may rely significantly on pigment strand cells. These cells are already well differentiated at 5 DPA. Our observations suggest little or no cell division in these four flanking cell types as the grain develops. They greatly enlarge and further differentiate by accumulation and synthesis of materials 
question; to what extent does assimilate supply to other grain cell types deprive Brachypodium endosperm resources for starch synthesis? We plan to answer this question in a future experiment.

\section{Based on cell morphology, we identified only two types of nucellar projection cells in} Brachypodium, whereas three and four types of nucellar projection cells were identified in barley and wheat respectively (Thiel et al., 2008; Wang et al., 1994). However, as in barley and wheat, the nucellar projection cells closest to the pigment strand were the least differentiated and those closest to the endosperm had massive cell walls. Compared to wheat and barley nucellar projection cells do not undergo extensive autolysis as the grain develops in Brachypodium.

The limited lysing of nucellar projection cells (Fig. 2d-e) creates a transient cavity that is smaller but similar to the endosperm cavity of wheat and barley. The endosperm cavity serves as a temporary apoplastic sink for assimilates (H. L. Wang, C. E. Offler, et al., 1995; H. L. Wang, J. W. Patrick, et al., 1995). The presence of endosperm cavity contribute to grain shape in cereals (Hands et al., 2012). Thus, the transient endosperm cavity contribute to the narrow crease in a mature Brachypodium grains (Hands and Drea, 2012).

Whereas nucellar cells in barley, maize, rice, sorghum and wheat usually undergo programmed cell death (PCD) and lyse after fertilization (Radchuk and Borisjuk, 2014), Brachypodium nucellar cells are slow to die and the nucellar epidermis remain prominent and persistent throughout grain development (Solomon and Drea, unpubl. data). Remarkably, the cell walls of nucellar projection cells in developing Brachypodium grains become thick, but lack wall ingrowths as found in barley and wheat (Cochrane and Duffus, 1980; Wang et al., 1994). Wall ingrowths in nucellar projection cells and other types of transfer cells, potentially increase plasma membrane surface area for rapid assimilate transport (Offler et al., 2003; H. L. Wang, C. E. Offler, et al., 1995).

It is tempting to speculate that the lack of wall ingrowths in nucellar projection cells of Brachypodium grains may contribute to lower post-phloem assimilate transport capacity compared to wheat and barley. This speculation is plausible considering that assimilate delivery to developing barley and wheat endosperms relies only on nucellar projection cells for passage of assimilates from the pigment strand into the endosperm cavity. Hence the need for the increased surface area for rapid assimilate movement. Whereas in Brachypodium, assimilates are also transported through nucellar epidermis (Fig. 4), in addition to the nucellar projection. This additional channel for assimilate movement probably means that less assimilate pass through Brachypodium nucellar projection cells compared to wheat and barley. However, numerous plasmodesmata connection 
379

380

381

382

383

384

385

386

387

388

389

390

391

392

393

394

395

396

397

398

399

400

401

402

403

404

405

406

407

408

409

410

411

412

between cells of Brachypodium nucellar projection cells (despite thickened cell walls) suggest a capacity for rapid assimilate movement across these cells. The thick walls of Brachypodium nucellar projection cells may also provide apoplastic route of assimilate and water movement towards the endosperm as reported in wheat (H. L. Wang, C. E. Offler, et al., 1995).

Assimilate movement into Brachypodium endosperm is identical to rice where the main supply route is circumferentially via the nucellar epidermis (Fig. 1b). In rice, several sucrose transport genes have been shown to be expressed along the post-phloem assimilate delivery pathway to developing grains (Bai et al., 2016; Furbank et al., 2001; Ma et al., 2017). While some of the genes have active roles in sucrose export from the nucellar epidermis into the maternal/filial apoplast, others have been linked with assimilate import into aleurone cells (Ma et al., 2017). Mutation of sucrose transport genes and/or their regulators negatively affects grain filling and lead to abnormally shaped rice grains (Bai et al., 2016; Ma et al., 2017; Wu et al., 2018). Though sucrose transport genes are conserved in Brachypodium (Braun and Slewinski, 2009), their role in assimilate transport and grain filling is yet to be reported. Nevertheless, a major structural difference is that in rice, nucellar epidermis cells collapse during grain development while in Brachypodium they persist till grain maturity. Based on earlier histological studies, it was suggested that mechanical compression of rice nucellar epidermis by expanding endosperm prevents further flow of assimilates and terminate grain filling (Ellis and Chaffey, 1987; Ellis et al., 1987). However, recent findings have demonstrated programmed cell death (PCD) in nucellar tissues of developing rice grains (Yang et al., 2012; Yin and Xue, 2012). It has also been shown that perturbation of genes involved in PCD of nucellar tissues adversely affects grain filling and lead to abnormally shaped grains (Nayar et al., 2013; Yang et al., 2012; Yin and Xue, 2012). Furthermore, PCD of nucellar tissues is known to be generally necessary for normal grain development in cereals (Domínguez and Cejudo, 2014; Lu and Magnani 2018). It is therefore remarkable that normal grain development and filling in Brachypodium does not require disintegration of nucellar epidermis cells. We previously showed that nucellar epidermis cells are dead in mature Brachypodium grain (Hands et al., 2012). However, there is no data yet on when and how its death affects grain development and filling. An additional feature of Brachypodium nucellar epidermis cells is accumulation (1-3) (1-4)- $\beta$-D glucan as the grain develops (Guillon et al., 2012). It is not clear if and how accumulation of (1-3) (1-4)- $\beta$ D glucan in nucellar epidermis cells affect assimilate transport through these cells. It is possible that (1-3) (1-4)- $\beta$-D glucan accumulation in the nucellar epidermis cells deprive the endosperm of assimilates and decrease the rate of assimilate transport. 


\section{Conclusion}

414 The fine structure and post-phloem assimilate transport into developing grains of Brachypodium

415 reflects the species phylogenetic position between Ehrhartoideae and Pooideae. Brachypodium

416 post-phloem assimilate delivery pathway is structurally similar to wheat and barley save for the

417 absence of modified aleurone. Its assimilate delivery strategy on the other hand is identical rice.

418 These combination of temperate anatomy with tropical physiology marks Brachypodium as an

419 excellent model to understand the evolution of specialised assimilate transfer cells (modified

420 aleurone) for efficient assimilate acquisition in temperate cereal grains. Such knowledge can be

421 exploited in domestication of new crop species.

422

\section{Acknowledgements}

424 We are grateful to Natalie Allcock and Anna Straatman-Iwanowska for assistance with grain

425 sectioning and electron microscopy. CUS is a PhD student funded by Tertiary Education Trust

426 Fund, Nigeria.

\section{References}

Bai, A.-N., Lu, X.-D., Li, D.-Q., Liu, J.-X., Liu, C.-M., 2016. NF-YB1-regulated expression of sucrose transporters in aleurone facilitates sugar loading to rice endosperm. Cell Research 26, 384-388. https://doi.org/10.1038/cr.2015.116 
Bihmidine, S., Hunter, C.T.I., Johns, C.E., Koch, K.E., Braun, D.M., 2013. Regulation of assimilate import into sink organs: Update on molecular drivers of sink strength. Frontiers in Plant Science 4. https://doi.org/10.3389/fpls.2013.00177

Bosnes, M., Weideman, F., Olsen, O.-A., 1992. Endosperm differentiation in barley wild- type and sex mutants. The Plant Journal 2, 661-674. https://doi.org/10.1111/j.1365-313X.1992.tb00135.X

Braun, D.M., Slewinski, T.L., 2009. Genetic Control of Carbon Partitioning in Grasses:

Roles of Sucrose Transporters and Tie-dyed Loci in Phloem Loading. Plant Physiology 149, 71-81. https://doi.org/10.1104/pp.108.129049

Cheng, W.H., Taliercio, E.W., Chourey, P.S., 1996. The Miniature1 Seed Locus of Maize Encodes a Cell Wall Invertase Required for Normal Development of Endosperm and Maternal Cells in the Pedicel. The Plant Cell 8, 971-983. https://doi.org/10.1105/tpc.8.6.971

Cochrane, M.P., 1985. Assimilate Uptake and Water Loss in Maturing Barley Grains. Journal of Experimental Botany 36, 770-782. https://doi.org/10.1093/jxb/36.5.770

Cochrane, M.P., Duffus, C.M., 1980. The nucellar projection and modified aleurone in the crease region of developing caryopses of barley (Hordeum vulgare L. var.Distichum).

Protoplasma 103, 361-375. https://doi.org/10.1007/BF01276962

Doebley, J.F., Gaut, B.S., Smith, B.D., 2006. The Molecular Genetics of Crop Domestication. Cell 127, 1309-1321. https://doi.org/10.1016/j.cell.2006.12.006

Domínguez, F., Cejudo, F.J., 2014. Programmed cell death (PCD): An essential process of cereal seed development and germination. Frontiers in Plant Science 5.

https://doi.org/10.3389/fpls.2014.00366

Donovan, G.R., Jenner, C.F., Lee, J.W., Martin, P., 1983. Longitudinal Transport of Sucrose and Amino Acids in the Wheat Grain. Functional Plant Biology 10, 31-42. https://doi.org/10.1071/pp9830031

Ellis, J.R., Chaffey, N.J., 1987. Structural Differentiation of the Nucellar Epidermis in the Caryopsis of Rice (Oryza sativa). Annals of Botany 60, 671-675.

https://doi.org/10.1093/oxfordjournals.aob.a087498

Ellis, J.R., Gates, P.J., Boulter, D., 1987. Storage-protein Deposition in the Developing Rice Caryopsis in Relation to the Transport Tissues. Annals of Botany 60, 663-670. https://doi.org/10.1093/oxfordjournals.aob.a087497

Felker, F.C., Peterson, D.M., Nelson, O.E., 1985. Anatomy of Immature Grains of Eight Maternal Effect Shrunken Endosperm Barley Mutants. American Journal of Botany 72, 248-256. https://doi.org/10.1002/j.1537-2197.1985.tb08289.x

Felker, F.C., Peterson, D.M., Nelson, O.E., 1984. Development of tannin vacuoles in chalaza and seed coat of barley in relation to early chalazal necrosis in the seg1 mutant. Planta 161, 540-549. https://doi.org/10.1007/BF00407087 
Felker, F.C., Peterson, D.M., Nelson, O.E., 1983. Growth Characteristics, Grain Filling, and Assimilate Transport in a Shrunken Endosperm Mutant of Barley. Plant Physiology 72, 679-684. https://doi.org/10.1104/pp.72.3.679

Felker, F.C., Shannon, J.C., 1980. Movement of 14C-labeled Assimilates into Kernels of Zea mays L: III. AN ANATOMICAL EXAMINATION AND MICROAUTORADIOGRAPHIC STUDY OF ASSIMILATE TRANSFER. Plant Physiology 65, 864-870. https://doi.org/10.1104/pp.65.5.864

Fisher, D.B., Gifford, R.M., 1986. Accumulation and Conversion of Sugars by Developing Wheat Grains: VI. Gradients Along the Transport Pathway from the Peduncle to the Endosperm Cavity during Grain Filling. Plant Physiology 82, 1024-1030. https://doi.org/10.1104/pp.82.4.1024

Frazier, J.C., Appalanaidu, B., 1965. The Wheat Grain during Development with Reference to Nature, Location, and Role of Its Translocatory Tissues. American Journal of Botany 52, 193-198. https://doi.org/10.1002/j.1537-2197.1965.tb06775.x

Furbank, R.T., Scofield, G.N., Hirose, T., Wang, X.-D., Patrick, J.W., Offler, C.E., 2001. Cellular localisation and function of a sucrose transporter OsSUT1 in developing rice grains. Functional Plant Biology 28, 1187-1196. https://doi.org/10.1071/pp01111

Guillon, F., Larré, C., Petipas, F., Berger, A., Moussawi, J., Rogniaux, H., Santoni, A., Saulnier, L., Jamme, F., Miquel, M., Lepiniec, L., Dubreucq, B., 2012. A comprehensive overview of grain development in Brachypodium distachyon variety Bd21. Journal of Experimental Botany 63, 739-755. https://doi.org/10.1093/jxb/err298

Hands, P., Drea, S., 2012. A comparative view of grain development in Brachypodium distachyon. Journal of Cereal Science, Cereal Grain Development: Molecular Mechanisms and Impacts on Grain Composition and Functionality 56, 2-8. https://doi.org/10.1016/j.jcs.2011.12.010

Hands, P., Kourmpetli, S., Sharples, D., Harris, R.G., Drea, S., 2012. Analysis of grain characters in temperate grasses reveals distinctive patterns of endosperm organization associated with grain shape. Journal of Experimental Botany 63, 6253-6266. https://doi.org/10.1093/jxb/ers281

Kosina, R., Tomaszewska, P., 2016. Variability of breeding system, caryopsis microstructure and germination in annual and perennial species of the genus Brachypodium P. Beauv. Genetic Resources and Crop Evolution 63, 1003-1021. https://doi.org/10.1007/s10722-015-0297-4

Krishnan, S., Dayanandan, P., 2003. Structural and histochemical studies on grain-filling in the caryopsis of rice (Oryza sativa L.). Journal of Biosciences 28, 455-469.

https://doi.org/10.1007/BF02705120

Lingle, S.E., Chevalier, P., 1985. Development of the Vascular Tissue of the Wheat and Barley Caryopsis as Related to the Rate and Duration of Grain Filling 1. Crop Science 25, 123-128. https://doi.org/10.2135/cropsci1985.0011183X002500010031x

Lu, J., Magnani, E., 2018. Seed tissue and nutrient partitioning, a case for the nucellus. Plant Reproduction 31, 309-317. https://doi.org/10.1007/s00497-018-0338-1 
Ma, L., Zhang, D., Miao, Q., Yang, J., Xuan, Y., Hu, Y., 2017. Essential Role of Sugar Transporter OsSWEET11 during the Early Stage of Rice Grain Filling. Plant and Cell Physiology 58, 863-873. https://doi.org/10.1093/pcp/pcx040

Maness, N.O., McBee, G.G., 1986. Role of Placental Sac in Endosperm Carbohydrate Import in Sorghum Caryopses 1. Crop Science 26, 1201-1207. https://doi.org/10.2135/cropsci1986. 0011183X002600060026x

Miller, M.E., Chourey, P.S., 1992. The Maize Invertase-Deficient miniature-1 Seed Mutation Is Associated with Aberrant Pedicel and Endosperm Development. The Plant Cell 4, 297-305. https://doi.org/10.1105/tpc.4.3.297

Nayar, S., Sharma, R., Tyagi, A.K., Kapoor, S., 2013. Functional delineation of rice MADS29 reveals its role in embryo and endosperm development by affecting hormone homeostasis. Journal of Experimental Botany 64, 4239-4253. https://doi.org/10.1093/jxb/ert231

Offler, C.E., McCurdy, D.W., Patrick, J.W., Talbot, M.J., 2003. Transfer Cells: Cells Specialized for a Special Purpose. Annual Review of Plant Biology 54, 431-454. https://doi.org/10.1146/annurev.arplant.54.031902.134812

Opanowicz, M., Hands, P., Betts, D., Parker, M.L., Toole, G.A., Mills, E.N.C., Doonan, J.H., Drea, S., 2011. Endosperm development in Brachypodium distachyon. Journal of Experimental Botany 62, 735-748. https://doi.org/10.1093/jxb/erq309

Oparka, K.J., Gates, P., 1981. Transport of assimilates in the developing caryopsis of rice (Oryza sativa L.). Planta 151, 561-573. https://doi.org/10.1007/BF00387436

Oparka, K.J., Gates, P.J., 1982. Ultrastructure of the developing pigment strand of rice (Oryza sativa L.) in relation to its role in solute transport. Protoplasma 113, 33-43. https://doi.org/10.1007/BF01283037

Porter, G.A., Knievel, D.P., Shannon, J.C., 1985. Sugar Efflux from Maize (Zea mays L.) Pedicel Tissue. Plant Physiology 77, 524-531. https://doi.org/10.1104/pp.77.3.524

Radchuk, V., Borisjuk, L., 2014. Physical, metabolic and developmental functions of the seedcoat. Frontiers in Plant Science 5. https://doi.org/10.3389/fpls.2014.00510

Sosso, D., Luo, D., Li, Q.-B., Sasse, J., Yang, J., Gendrot, G., Suzuki, M., Koch, K.E., McCarty, D.R., Chourey, P.S., Rogowsky, P.M., Ross-Ibarra, J., Yang, B., Frommer, W.B., 2015. Seed filling in domesticated maize and rice depends on SWEET-mediated hexose transport. Nature Genetics 47, 1489-1493. https://doi.org/10.1038/ng.3422

Thiel, J., Weier, D., Sreenivasulu, N., Strickert, M., Weichert, N., Melzer, M., Czauderna, T., Wobus, U., Weber, H., Weschke, W., 2008. Different Hormonal Regulation of Cellular Differentiation and Function in Nucellar Projection and Endosperm Transfer Cells: A Microdissection-Based Transcriptome Study of Young Barley Grains. Plant Physiology 148, 1436-1452. https://doi.org/10.1104/pp.108.127001

Thorne, J.H., 1985. Phloem Unloading of C and N Assimilates in Developing Seeds. Annual Review of Plant Physiology 36, 317-343. https://doi.org/10.1146/annurev.pp.36.060185.001533 
van Bel, A.J.E., Hess, P.H., 2008. Hexoses as phloem transport sugars: The end of a dogma? Journal of Experimental Botany 59, 261-272. https://doi.org/10.1093/jxb/erm294

Wang, E., Wang, J., Zhu, X., Hao, W., Wang, L., Li, Q., Zhang, L., He, W., Lu, B., Lin, H., Ma, H., Zhang, G., He, Z., 2008. Control of rice grain-filling and yield by a gene with a potential signature of domestication. Nature Genetics 40, 1370-1374. https://doi.org/10.1038/ng.220

Wang, H.L., Offler, C.E., Patrick, J.W., 1995. The cellular pathway of photosynthate transfer in the developing wheat grain. II. A structural analysis and histochemical studies of the pathway from the crease phloem to the endosperm cavity. Plant, Cell \& Environment 18, 373-388.

https://doi.org/10.1111/j.1365-3040.1995.tb00373.x

Wang, H.L., Offler, C.E., Patrick, J.W., 1994. Nucellar projection transfer cells in the developing wheat grain. Protoplasma 182, 39-52. https://doi.org/10.1007/BF01403687

Wang, H.L., Patrick, J.W., Offler, C.E., Wang, X.-D., 1995. The cellular pathway of photosynthate transfer in the developing wheat grain. III. A structural analysis and physiological studies of the pathway from the endosperm cavity to the starchy endosperm. Plant, Cell \& Environment 18, 389407. https://doi.org/10.1111/j.1365-3040.1995.tb00374.x

Wu, X., Liu, J., Li, D., Liu, C.-M., 2016. Rice caryopsis development I: Dynamic changes in different cell layers. Journal of Integrative Plant Biology 58, 772-785. https://doi.org/10.

1111/jipb.12440

Wu, Y., Lee, S.-K., Yoo, Y., Wei, J., Kwon, S.-Y., Lee, S.-W., Jeon, J.-S., An, G., 2018.

Rice Transcription Factor OsDOF11 Modulates Sugar Transport by Promoting Expression of Sucrose Transporter and SWEET Genes. Molecular Plant 11, 833-845.

https://doi.org/10.1016/j.molp.2018.04.002

Yang, X., Wu, F., Lin, X., Du, X., Chong, K., Gramzow, L., Schilling, S., Becker, A., Theißen, G., Meng, Z., 12AD-2012. Live and Let Die - The Bsister MADS-Box Gene OsMADS29 Controls the Degeneration of Cells in Maternal Tissues during Seed Development of Rice (Oryza sativa). PLOS ONE 7, e51435. https://doi.org/10.1371/journal.pone.0051435

Yin, L.-L., Xue, H.-W., 2012. The MADS29 Transcription Factor Regulates the Degradation of the Nucellus and the Nucellar Projection during Rice Seed Development. The Plant Cell 24, 1049-1065. https://doi.org/10.1105/tpc.111.094854

Zee, S.-Y., O'brien, T.P., 1970. Studies on the Ontogeny of the Pigment Strand in the Caryopsis of Wheat. Australian Journal of Biological Sciences 23, 1153-1172. https://doi.org/10.1071/bi9701153

Zheng, Y., Wang, Z., 2011. Contrast observation and investigation of wheat endosperm transfer cells and nucellar projection transfer cells. Plant Cell Reports 30, 1281-1288.

https://doi.org/10.1007/s00299-011-1039-5

Zheng, Y., Xiong, F., Wang, Z., Gu, Y., 2015. Observation and investigation of three endosperm transport tissues in sorghum caryopses. Protoplasma 252, 705-714. https://doi.org/10.1007/s00709$\underline{014-0705-1}$ 


\section{Figure labels}

Fig. 1: Caryopsis Endosperm Assimilate Acquisition Route (CEAAR) models. The models illustrate how resources are mobilized into the endosperm of grass caryopsis.

Fig. 2: Development of Brachypodium distachyon grain post-phloem assimilate transport pathway. (a)Transverse section of a Brachypodium grain at 10 days post anthesis (DPA). Red square indicates area magnified in subsequent images. (b), (c), (d), (e), (f), and (g) are sections Brachypodium grain post-phloem assimilate transport route at 5, 10, 15, 20, 25, and 30 DPA respectively. Sieve elementcompanion cell complex were present in the vascular bundle all sections. There was progressive accumulation of dark deposits in the pigment strand as the grain develops. Cell death and disintegration of nucellar projection cells closest to the endosperm was observed from 10 DPA and is indicated with arrow heads. This created a transient endosperm cavity present at 15 and 20 DPA. The thickness of nucellar epidermis cell wall adjoining the endosperm increased as the grain developed. Bar = $0.1 \mathrm{~mm}$. Al, aleurone cells; TC, tube cell; EC, endosperm cavity; II, inner integument; NE, Mc, mesocarp; nucellar epidermis; NP, nucellar projection; OI, outer integument; PS, pigment strand; En, endosperm; VB, vascular bundle.

Fig. 3: Transmission electron micrographs of transverse sections of developing Brachypodium grains. (a) Vasuclar bundle at 20 DPA. Note the prominent nucleus and presence of numerous mitochondria (M) in the dense cytoplasm of the vascular paranchyma (VP) cells. Enucleate seive elements (SE) are also present. Bar $=5 \mu \mathrm{m}$. (b) Shows chloroplasts (CL) in photosynthetic mesocarp cells followed by tube cells (TC), outer integument (OI), inner integument (II), and nucellar epidermis (NE). Thick deposits of cutin on the outer integument cell walls adjoining cross cells is with arrow heads. Bar $=10 \mu \mathrm{m}$. (c) Nucellar projection (NP) cells nearest the pigment strand (PS) have dense cytoplasm at 20 DPA. Bar $=5 \mu \mathrm{m}$. (d) Mitochondria is present in pigment strand cells whether dark deposits (DD) occur in those cells or not. Bar $=2 \mu \mathrm{m}$. (e) A section through adjacent inner integument cell and and a nucellar epidermis cell. Note the prominent plasmalemma between the cells. The cell wall of the nucellar epidermis cell has rich deposit of cellulose indicated with arrow heads. Bar $=2 \mu \mathrm{m}$. (f) At $30 \mathrm{DPA}$, the nucellar projection has dense cytoplasm and massive cell walls with frequent plasmodesmata connections (indicated with arrow heads). Bar $=5$ $\mu \mathrm{m}$. 
Fig. 4: Delineation of assimilate transport route into Brachypodium endosperm using 5(6)carboxyfluorescein diacetate (CFDA). (a), (b), (c), and (d) are free hand transverse section of 20 DPA Brachypodium grains. (a) and (b) shows ventral and lateral portions of sections that were incubated for $15 \mathrm{~min}$ in distilled water as control. There is auto fluorescence in the epicarp (Ec). (c) and (d) are similar portions of sections made from grains that were incubated in for $15 \mathrm{~min}$ in $0.01 \%$ CFDA. The dye signal is distinct in the vascular bundle (VB), nucellar projection (NP), nucellar epidermis (NE), and endosperm (En). Bar $=0.05 \mathrm{~mm}$. 
bioRxiv preprint doi: https://doi.org/10.1101/718569; this version posted July 30, 2019. The copyright holder for this preprint (which was not certified by peer review) is the author/funder, who has granted bioRxiv a license to display the preprint in perpetuity. It is made available under aCC-BY 4.0 International license.

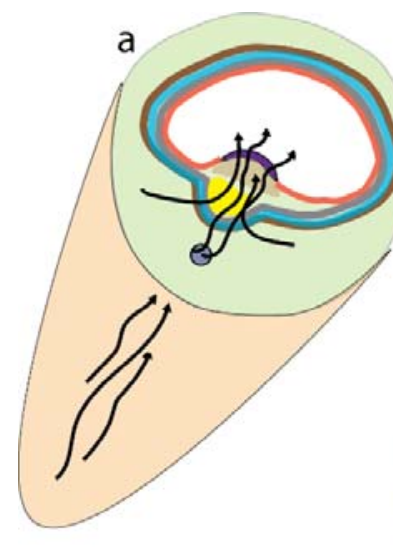

Ventral Direct

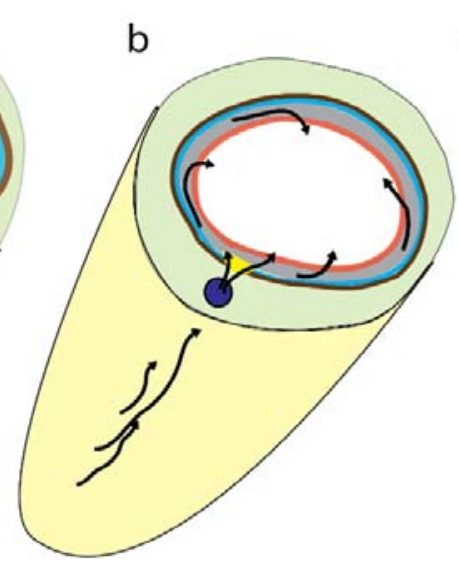

Ventral Circuitous c

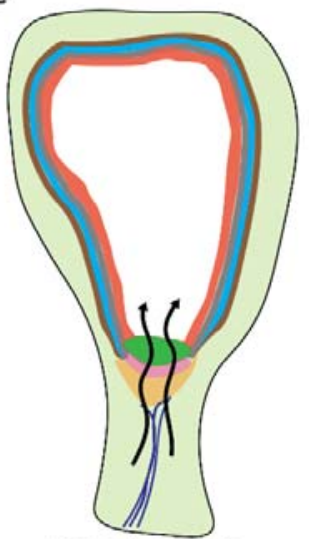

Basal direct
Legend

Pericarp

Outer Integument

Inner Integument

Aleurone Layer

Nucellar epidermis

Basal Endosperm Transfer Layer

Placento-chalaza Region

Endosperm Cavity

Modified Aleuron

Nucellar Projection

Vascular Bundle

$\square$ starchy Endosperm

Placental Sac

Fig 1 
bioRxiv preprint doi: https://doi.org/10.1101/718569; this version posted July 30,2019. The copyright holder for this preprint (which was not certified by peer review) is the author/funder, who has granted bioRxiv a license to display the preprint in perpetuity. It is made available under aCC-BY 4.0 International license.
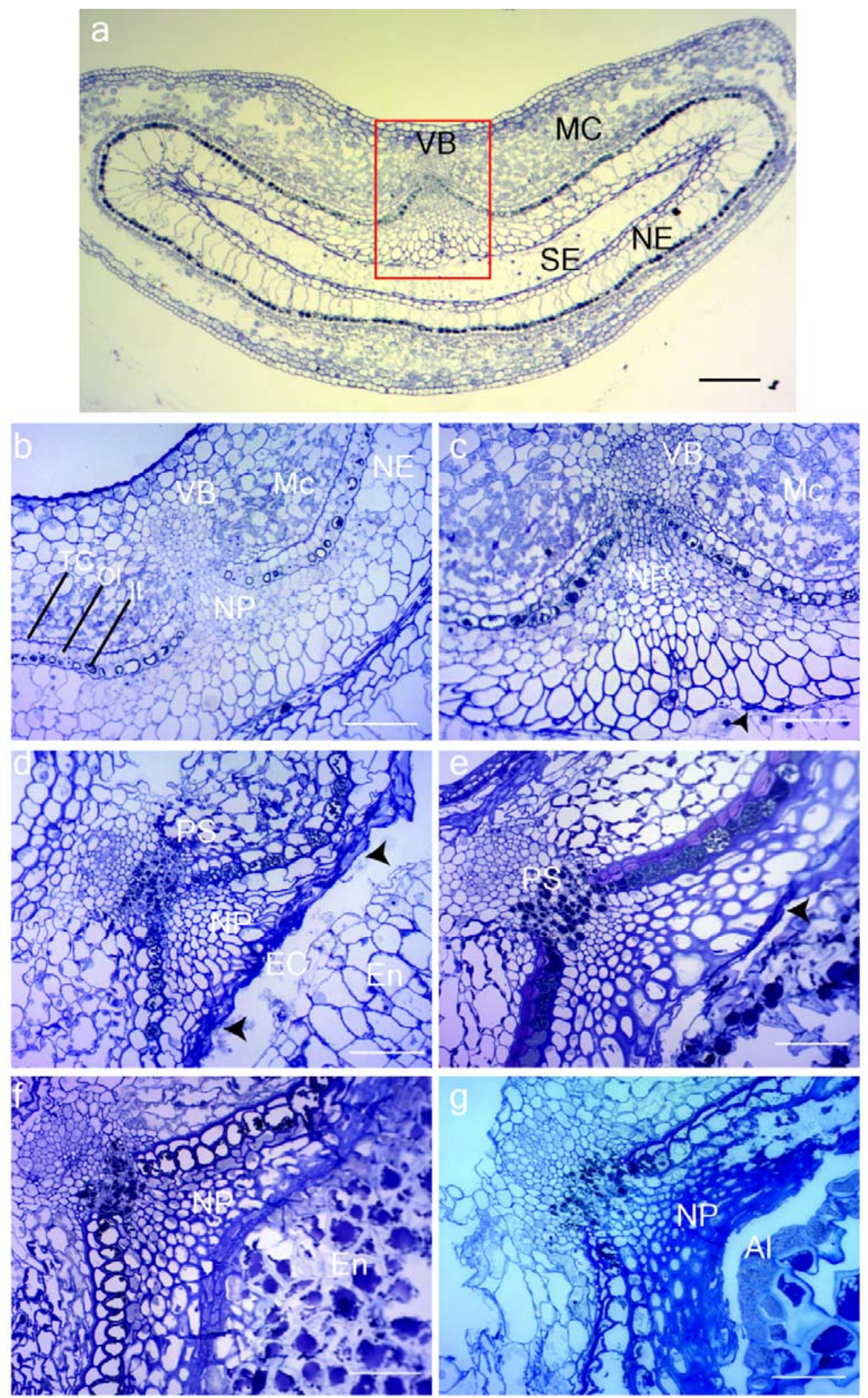

Fig 2 
bioRxiv preprint doi: https://doi.org/10.1101/718569; this version posted July 30, 2019. The copyright holder for this preprint (which was not certified by peer review) is the author/funder, who has granted bioRxiv a license to display the preprint in perpetuity. It is made available under aCC-BY 4.0 International license.
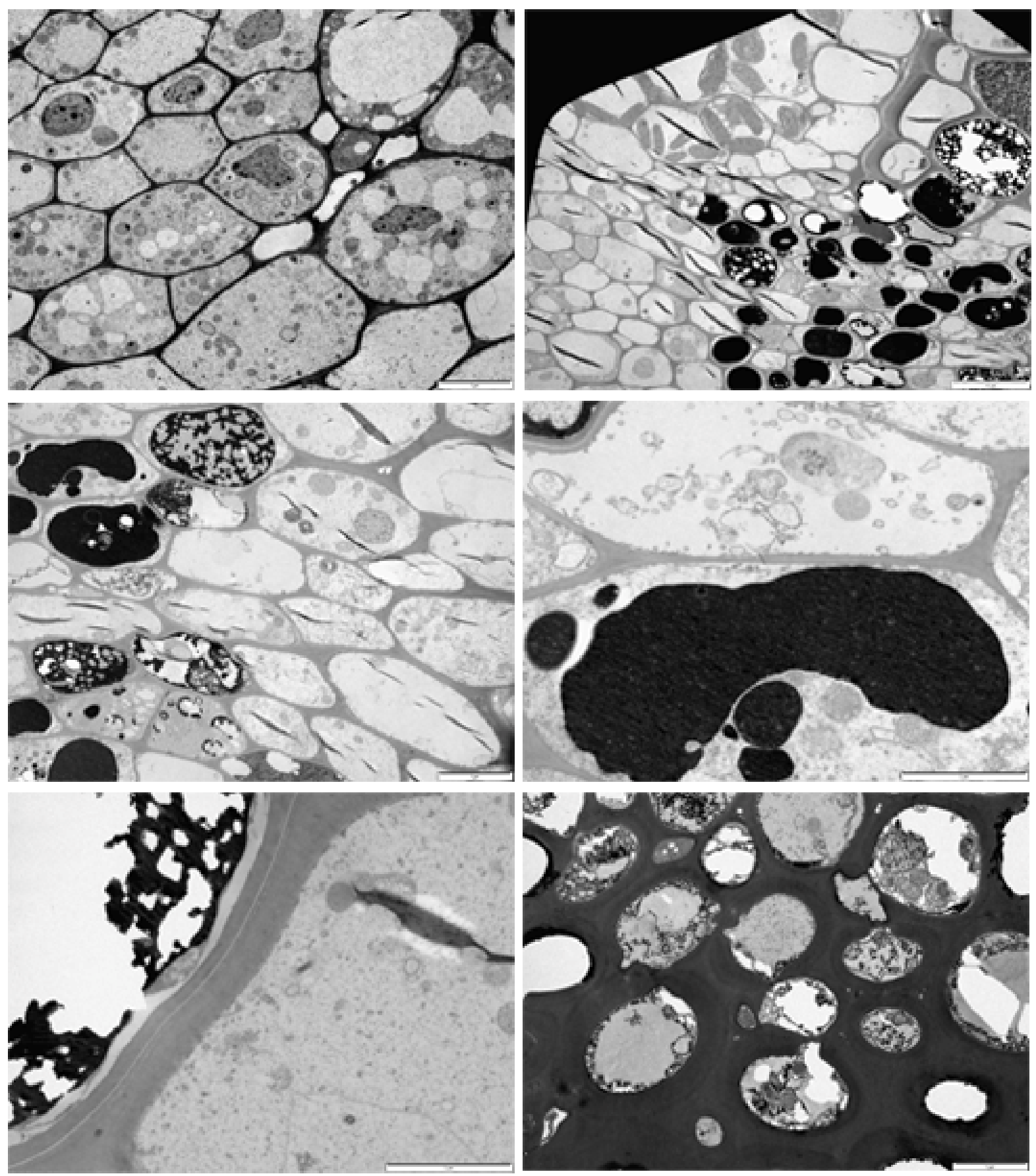

Fig 3 
bioRxiv preprint doi: https://doi.org/10.1101/718569; this version posted July 30, 2019. The copyright holder for this preprint (which was not certified by peer review) is the author/funder, who has granted bioRxiv a license to display the preprint in perpetuity. It is made available under aCC-BY 4.0 International license.
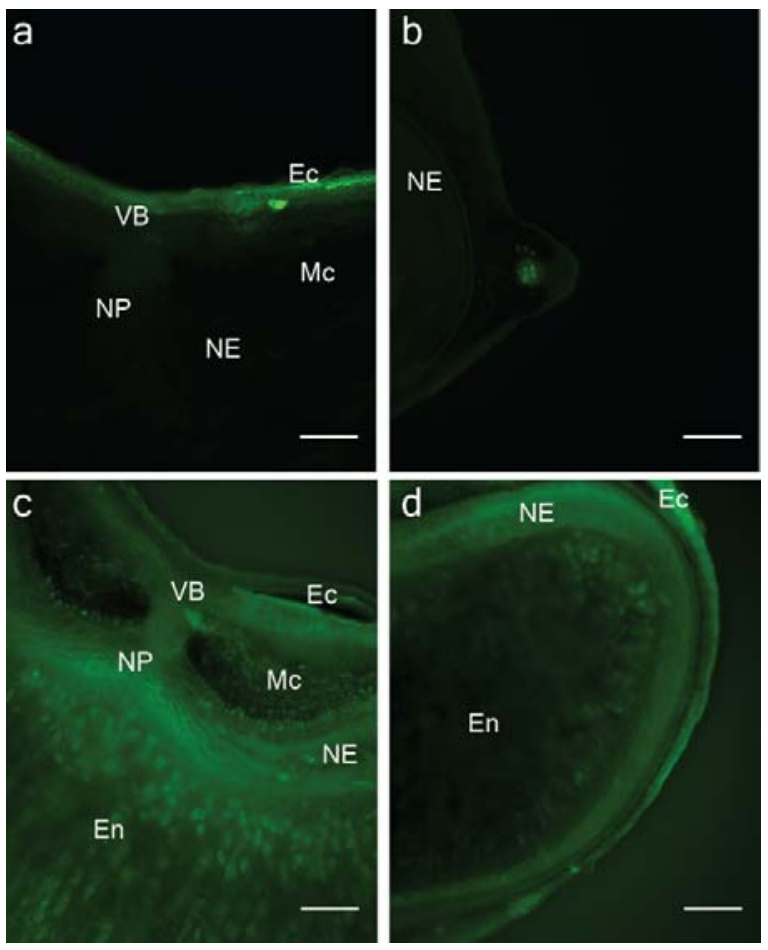

Fig 4. 